\title{
Assessing the Temporal Variability and Drivers of Transparent Exopolymer Particle Concentrations and Production Rates in a Subtropical Estuary
}

\author{
Elizabeth L. Harvey ${ }^{1}$ (D) S Sean R. Anderson ${ }^{2,3} \cdot$ Quintin Diou-Cass $^{4} \cdot$ Patrick I. Duffy ${ }^{5}$
}

Received: 4 August 2020 / Revised: 25 September 2020 / Accepted: 2 October 2020 / Published online: 13 October 2020

(C) The Author(s) 2020

\begin{abstract}
Transparent exopolymer particles (TEP) are the central mechanism by which carbon is shuttled from the surface to the deep ocean. Despite the importance of these particles, the magnitude and drivers of temporal variability in the concentration and production rate of TEP in the ocean are not well resolved, especially in highly dynamic and productive regions like estuaries. Here, TEP dynamics were evaluated across weekly, tidal, and diel time scales within the Skidaway River Estuary (GA, USA) and adjacent coastal waters in the South Atlantic Bight. No significant trends in TEP concentration or production rates were observed over weekly time scales, though over tidal cycles, TEP concentration varied between tide stage and TEP:chlorophyll ratios were always lower at low relative to high tides. Over sequential diel cycles, TEP concentrations were two times higher at night relative to midday. Different biological and environmental variables were correlated with TEP dynamics (Spearman $\rho$ ) depending on the time scale considered, reinforcing the importance of time-specific drivers of TEP. These results emphasize the importance in considering the temporal variability of field-based TEP measurements, with implications for accurate assessments of carbon cycling in coastal ecosystems and the incorporation of TEP into carbon export models.
\end{abstract}

Keywords Transparent exopolymer particle $\cdot$ TEP $\cdot$ Temporal variability $\cdot$ Diel

\section{Introduction}

Particle attachment and/or aggregation aided by transparent exopolymer particles (TEP) is one of the most common

Communicated by Zhanfei Liu

Electronic supplementary material The online version of this article (https://doi.org/10.1007/s12237-020-00847-5) contains supplementary material, which is available to authorized users.

Elizabeth L. Harvey

elizabeth.harvey@unh.edu

1 Department of Biological Sciences, University of New Hampshire, Durham, NH, USA

2 Northern Gulf Institute, Mississippi State University, Mississippi State, MS, USA

3 Ocean Chemistry and Ecosystems Division, Atlantic Oceanographic and Meteorological Laboratory, National Oceanic and Atmospheric Administration, Miami, FL, USA

4 Department of Marine and Coastal Sciences, Rutgers University, New Brunswick, NJ, USA

5 Skidaway Institute of Oceanography, University of Georgia, Savannah, GA, USA mechanisms that facilitates carbon export (Alldredge et al. 1993; Engel 2004), from the surface to the deep ocean. TEP are abiotically forming, gel-like particles that represent an important pathway and intermediary in the transformation between dissolved organic carbon (DOC) and particulate organic carbon (POC) and form the matrix of all marine snow particles (Alldredge et al. 1993; Passow and Alldredge 1995; Passow 2000). TEP precursors are both neutrally buoyant and sticky, and as a result, TEP accumulates in the surface microlayer, but also increases collision and coagulation rates with other suspended particles, often expediting (>50\% export efficiency) vertical sinking of organic matter via a cascading aggregation mechanism (Wurl et al. 2011).

Currently, there remains a high level of uncertainty associated with estimates of global carbon export flux, with reported estimates ranging from 5 to $16 \mathrm{Pg} \mathrm{C} \mathrm{y}^{-1}$ (Boyd and Trull 2007; Falkowski et al. 2011; Henson et al. 2015). This wide variability is partially driven by a poor understanding of the spatial and temporal dynamics of microbial interactions and export flux. In terms of TEP, a great deal of prior work has focused on establishing spatial measurements of TEP and testing factors that may drive in situ TEP dynamics (e.g., TEP formation and standing stock concentrations) such as sunlight, nutrients, and microbial 
community composition (Mari et al. 2017; Zamanillo et al. 2019a and references therein). Fewer accounts have been made of the temporal dynamics of TEP concentrations at a single geographic location (Bhaskar and Bhosle 2006; de Vicente et al. 2009; Engel et al. 2017; Morelle et al. 2017; Ortega-Retuerta et al. 2018), though such efforts have revealed shifts in TEP concentration over time. For instance, over a seasonal cycle in the Mediterranean Sea, significant differences in TEP concentrations were observed, reaching maximum values in summer $\left(224 \pm 7.9 \mu \mathrm{g} \mathrm{XG}\right.$ eq. $\left.\mathrm{L}^{-1}\right)$ and exhibiting strong correlations (Spearman $\rho>0.6$ ) with surface water temperature and stratification index (OrtegaRetuerta et al. 2018). Yet, in contrast, differences in TEP concentrations were not measured over shorter scales (e.g., diel cycles) in field experiments in the Southern Ocean (Zamanillo et al. 2019b). While these studies provide an important baseline for temporal TEP research, additional work is needed to capture the temporal mechanisms that drive TEP dynamics across a wide range of time scales (e.g., diel to weekly) that correspond to varying gradients in environmental and biological conditions.

Estuaries are carbon-rich areas of the ocean (Hopkinson and Smith 2005) and are highly dynamic, with significant daily and seasonal changes in environmental and biological gradients (Cloern and Jassby 2010). TEP has been shown to be an important contributor to carbon export within estuarine systems (Annane et al. 2015; Morelle et al. 2017; Lee et al. 2020), with high TEP concentrations commonly found in the maximum turbidity zone (MTZ), areas where suspended particulate material accumulates (Malpezzi et al. 2013). In addition, significant concentrations of TEP in estuaries could be derived from high inputs of terrestrial detrital material that is often partially remineralized by heterotrophic bacteria (Heip et al. 1995). Better constraining TEP dynamics in these areas of high complexity will help to assess reliable drivers of TEP and, ultimately, help to predict the biogeochemical effects of TEP on marine ecosystems and carbon export.

Here, we present TEP measurements from three separate temporal studies conducted in the Skidaway River Estuary (GA, USA) and nearshore waters (South Atlantic Bight), which involved sampling at weekly, tidal, and diel intervals. TEP measurements were correlated to environmental and biological factors that were measured concurrently to establish potential drivers of TEP dynamics across a range of time intervals. Our goals through this study were to (1) identify temporal patterns of TEP over time and (2) establish reliable drivers of temporal TEP dynamics that may drive future TEP research. Integrating temporal TEP measurements within coastal marine sampling will allow for better predictions of carbon cycling and flux estimates in these highly complex regions.

\section{Methods}

\section{Water Sampling Across Time Scales}

TEP samples were collected in triplicate from surface water $(1 \mathrm{~m})$ from the Skidaway River Estuary (latitude, $31^{\circ} 59^{\prime}$ $25.7^{\prime \prime} \mathrm{N}$; longitude, $81^{\circ} 01^{\prime} 19.7^{\prime \prime} \mathrm{W}$ ) via the dock at the Skidaway Institute of Oceanography. Water was collected by hand using a 5-L Niskin bottle. Weekly sampling occurred at high tide over a full year $(n=36$ samples; March 1, 2017, to February 21, 2018), while tidal sampling at same-day low vs. high tides spanned an 8 -week period in the summer $(n=16$ samples; June 22, 2017, to August 17, 2017). Tide height predictions were taken from a nearby station (NOAA ID: TEC3411); semidiurnal tides (6 h) in the estuary consistently ranged between 2 and $3 \mathrm{~m}$ and sampling dates rarely coincided with spring or neap tides (see Anderson et al. 2018 for more details). Sampling time varied depending on tide schedule, though typically occurred in the morning (near or after sunrise) and afternoon. Surface water temperature, salinity, and dissolved oxygen were measured at each sampling event using a YSI probe (YSI $600 \mathrm{QS}$ ).

In October 2017, triplicate TEP samples were collected at noon (local Eastern Time) and subsequently collected every $4 \mathrm{~h}$ over multiple diel cycles ( $n=13$ samples) from surface water $(5 \mathrm{~m})$ at a station in the South Atlantic Bight (latitude, $31^{\circ} 79^{\prime} 58^{\prime \prime} \mathrm{N}$; longitude, $80^{\circ} 78^{\prime} 44^{\prime \prime} \mathrm{W}$ ) aboard the R/V Savannah. Water was collected via CTD rosette with $10-\mathrm{L}$ Niskin bottles and the ship maintained a stationary location for all sampling points. Temperature, salinity, colored dissolved organic matter (CDOM), photosynthetically active radiation (PAR), and turbidity were measured using a CTD profiler (SBE 32) and datalogger (SBE 9).

Water was also collected $(50-100 \mathrm{ml})$ at each time point over the diel cycle to measure bulk chlorophyll. Briefly, chlorophyll $a$ samples were filtered in triplicate with $25-\mathrm{mm} 0.7-\mu \mathrm{m}$ $\mathrm{GF} / \mathrm{F}$ filters, extracted in the dark at room temperature for 12 $24 \mathrm{~h}$ in $91 \%$ ethanol and measured on a Turner AU10 fluorometer (Jespersen and Christoffersen 1987; Graff and Rynearson 2011). Dilution experiments were performed at each time point, following a two-point approach (triplicate 20\% and 100\% whole seawater bottles; Morison and Menden-Deuer 2017). Bottles (1.2 L) were incubated on deck in a 300-L flow-through tank maintained at ambient light and temperature (using HOBO data loggers and screen mesh). Phytoplankton instantaneous growth $(\mu 0)$, microzooplankton grazing $(g)$, and net accumulation rates $(r=\mu 0-g)$ were estimated from 24-h changes in bulk chlorophyll concentration (Landry and Hassett 1982). Bottle incubation experiments do not allow for physical forcing to mediate TEP dynamics, and so are restricted to TEP production values as the result of biology. They can be used to gain insight into how the biological composition of the water column gives rise to differential TEP dynamics. 
A collection of environmental and biological measurements were taken concurrently with weekly and tidal TEP samples from the estuary and have been published elsewhere (Anderson et al. 2018; Anderson and Harvey 2019). These measurements include particulate organic carbon and nitrogen (POC and PON), dissolved inorganic nutrients, bulk chlorophyll, plankton community composition (via flow cytometry and FlowCam), and phytoplankton growth and mortality rates measured via two-point dilution experiments.

\section{TEP Quantification and Production}

For TEP quantification, triplicate $250 \mathrm{~mL}$ samples were gently siphoned into amber polycarbonate bottles and stored at ambient water temperature until filtration. All TEP samples (50$200 \mathrm{~mL}$ ) were gently $(<150 \mathrm{mbar})$ filtered through $25-\mathrm{mm}$ $0.40-\mu \mathrm{m}$ polycarbonate filters (Millipore, Isopore, HTTP02500) within $2 \mathrm{~h}$ of collection. Immediately after filtration, filters were stained with $500 \mu \mathrm{L}$ of a $0.04 \%$ Alcian Blue (AB) solution buffered with $0.06 \%$ acetic acid (pH 2.5) and frozen at $-20{ }^{\circ} \mathrm{C}$. All filters were then extracted within 1 month of collection. For extraction, filters were immersed in sulfuric acid (80\%) for at least $3 \mathrm{~h}$ and then measured spectrophotometrically for absorbance (Agilent $8453 \mathrm{UV}$-visible spectrophotometer) at a fixed wavelength of $787 \mathrm{~nm}$.

We used the recently updated method described in Bittar et al. (2018) to calibrate TEP measurements using xanthan gum (XG) calibration curves. Briefly, $\mathrm{AB}$ dye was calibrated to $\mathrm{XG}$ equivalence by staining a dilution series of known $\mathrm{XG}$ concentrations. Twelve separate $\mathrm{AB}$ solutions were used in the data presented here; their $f$ factors were between 96 and 203. TEP concentrations ( $\mu \mathrm{g} X \mathrm{X}$ eq. $\mathrm{L}^{-1}$ ) were calculated according to Bittar et al. (2018).

To estimate TEP production rates, we measured TEP concentrations within dilution experiment bottles from each time interval (diel to weekly), following the 24-h incubation period (conditions described above). Initial TEP samples $\left(\right.$ TEP $\left._{\text {initial }}\right)$ were compared with those measured after $24 \mathrm{~h}\left(\mathrm{TEP}_{\text {final }}\right)$ and net TEP production rates were calculated as $\left(\left[\mathrm{TEP}_{\text {final }}\right]-\left[\mathrm{TEP}_{\text {initial }}\right]\right) /\left[\mathrm{TEP}_{\text {initial }}\right]$, following production calculations from prior studies (Egge et al. 2009; Passow 2012).

\section{Statistics}

Paired $t$-tests were used to test the significant difference between TEP concentrations measured at same-day low and high tides and between seasons. Seasons were delineated as follows: Winter (December-February), Spring (March-May), Summer (June-August), and Fall (September-November). A one-way analysis of variance (ANOVA) with a Bonferroni's multiple comparisons test was used to test for significant differences across the diel sampling time points. For all statistical tests, significance was defined with $p$ values $<0.05$.

We used Spearman rank correlations to test the relationships between TEP measurements (TEP concentration, production, and TEP:chlorophyll) and environmental and biological factors that were measured at each respective time interval. We used the core $\mathrm{R}$ package stats (https://cran.r-project.org, V3.6.3) to perform Shapiro-Wilk normality tests (Shapiro and Wilk 1965) of the metadata variables (shapiro.test function) and subsequently measured Spearman correlation values using the cor.test function. Separate heatmaps showing Spearman correlations for each time interval (seasonal, tidal, and diel) were observed using the pheatmap function in the R package pheatmap (Kolde 2012; V1.0.12). Code for processing TEP correlations in $\mathrm{R}$ and associated metadata tables are available via GitHub (https:// github.com/sra34/TEP-Time).

\section{Results}

\section{Weekly}

Over the course of a year (March 1, 2017, to February 21, 2018), 36 TEP samples were collected in triplicate on a weekly interval. TEP concentrations ranged from a low of $130 \pm$ $10 \mu \mathrm{g} \mathrm{XG}$ eq. $\mathrm{L}^{-1}$ measured in February 2018 to a high of 690 $\pm 10 \mu \mathrm{g}$ XG eq. $\mathrm{L}^{-1}$ in July 2017 (Fig. 1a). No significant seasonal trend $(p>0.05)$ in TEP concentrations were observed throughout the year, with high variability in TEP concentrations from week to week. TEP:chl ratios ranged from $48 \pm 8$ to a high of $224 \pm 16$ in June 2017 (Fig. 1b). Similar to bulk TEP, the TEP:chl ratio exhibited significant variability throughout the year, with no clear seasonal trend. Net TEP production rates varied from $-0.22 \pm 0.03$ to a high of $1.65 \pm$ $0.11 \mu \mathrm{g} \mathrm{XG}$ eq. $\mathrm{L}^{-1} \mathrm{~d}^{-1}$ on March 1 (Fig. 1c). A negative net TEP production rate would indicate that TEP is being lost from the system. Similar to the other metrics, net TEP production rates did not demonstrate clear seasonal patterns, with rates often alternating between a positive and negative net TEP production rate on a weekly basis. TEP concentrations and production rates from the diel sampling intervals are available in SI Table 1.

\section{Tidal}

TEP concentrations varied over the tidal dataset, ranging from $328 \pm 85$ to $657 \pm 57 \mu \mathrm{g} \mathrm{XG}$ eq. $\mathrm{L}^{-1}$ at high tide and $238 \pm 15$ to $1342 \pm 15 \mu \mathrm{g} \mathrm{XG}$ eq. $\mathrm{L}^{-1}$ at low tide (Fig. 2a). TEP was significantly higher $(p<0.02)$ at low tide relative to high tide on three out of the eight experiments, whereas TEP was significantly higher $(p<0.01)$ on two occasions at high tide. 

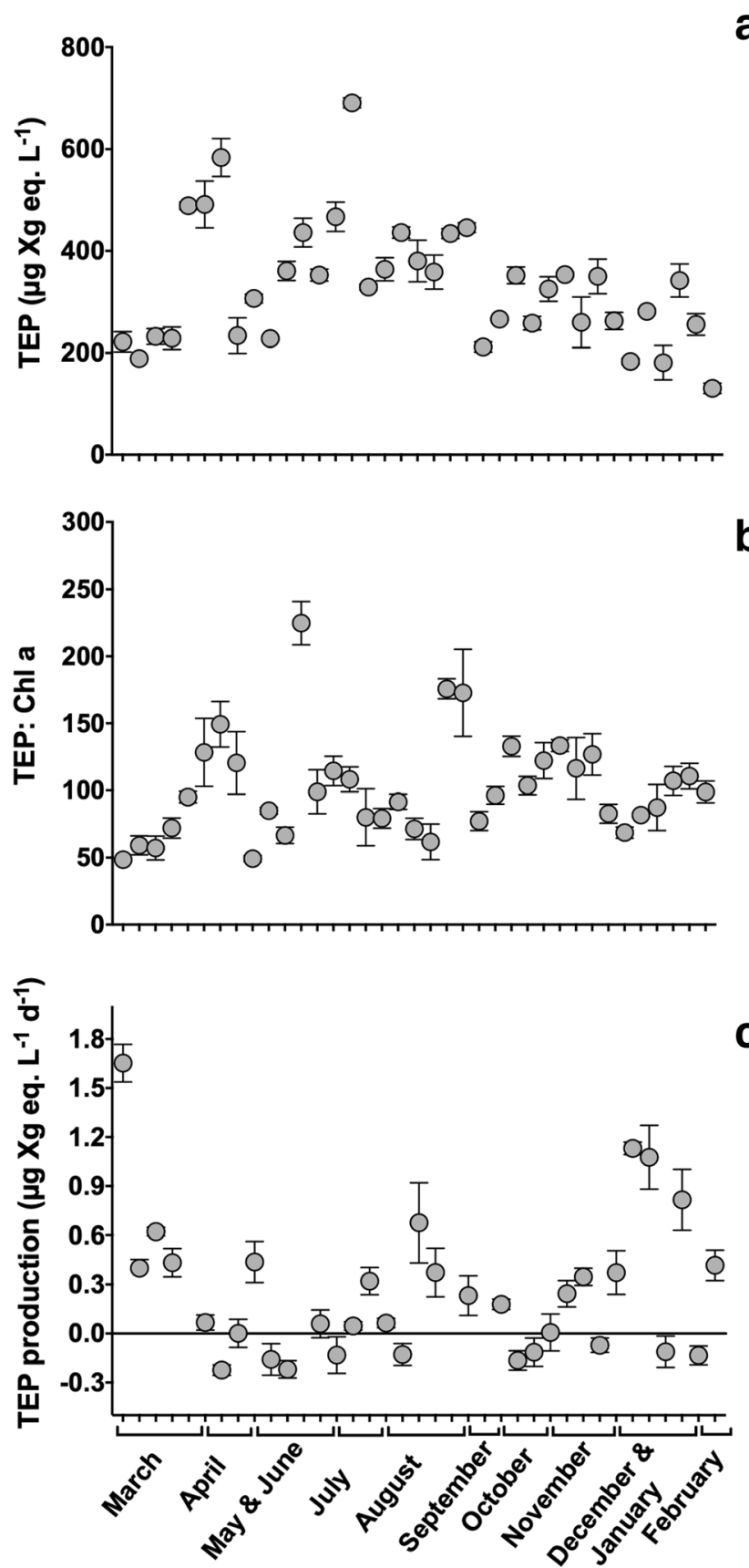

Fig. 1 Weekly measurements of a TEP concentration ( $\mu$ g XG eq. $\left.\mathrm{L}^{-1}\right)$, b TEP to chlorophyll ratio, and $\mathbf{c}$ TEP production rates ( $\mu \mathrm{g} \mathrm{XG} \mathrm{eq.} \mathrm{L}^{-1} \mathrm{~d}^{-1}$ ). Symbols are the mean of triplicate measurements, and error bars represent one standard deviation from the mean. Samples are grouped by month on the $x$-axis

TEP:chl ratios ranged from $71 \pm 8$ to $224 \pm 16$ at high tide compared with $23 \pm 2$ to $90 \pm 10$ at low tide (Fig. 2b). Interestingly, across all comparative tidal experiments, the ratio of TEP:chl at low tide was either significantly lower (five of eight experiments) or not significantly different from the ratio observed at high tide. This indicates that although high TEP concentrations were observed at low tide, the concentration of TEP per unit of chlorophyll at low tide was usually
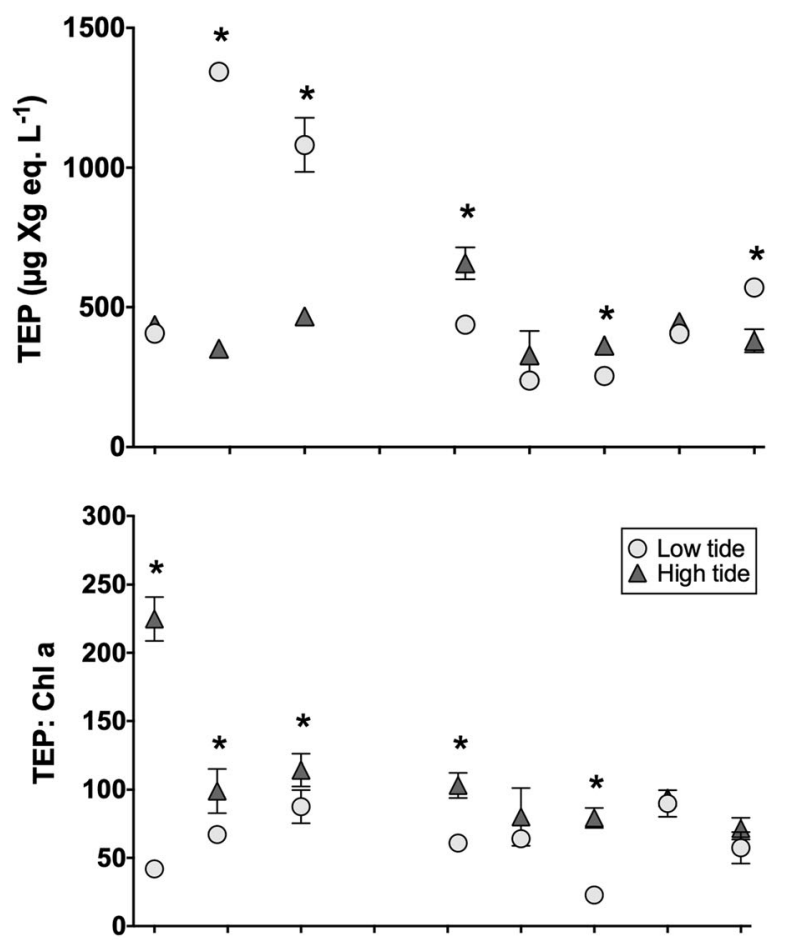

b

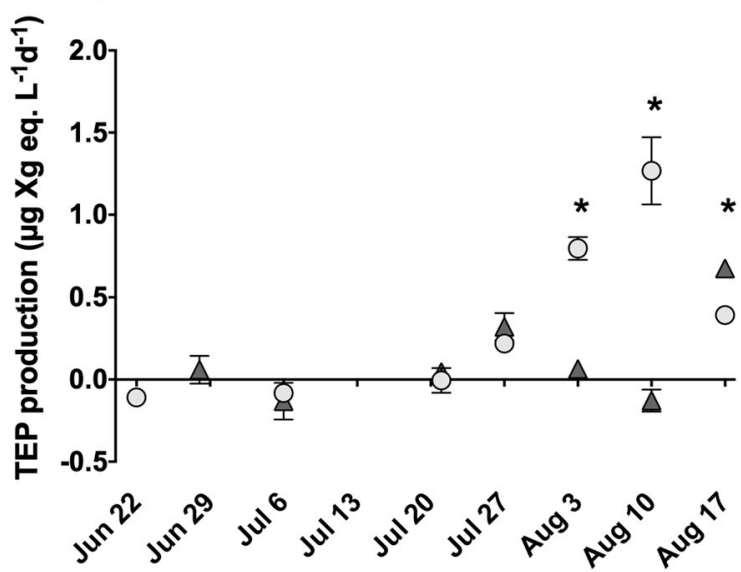

Fig. 2 Tidal measurements of a TEP concentration $\left(\mu g\right.$ XG eq. $\left.L^{-1}\right)$, b TEP to chlorophyll ratio, and $\mathbf{c}$ TEP production rates ( $\mu \mathrm{g} \mathrm{XG} \mathrm{eq.} \mathrm{L}^{-1} \mathrm{~d}^{-1}$ ). Symbols are the mean of triplicate measurements either at low (circles) or high (triangles) tides, and error bars represent one standard deviation from the mean. Tidal sampling was conducted from Jun 22 to Aug 17 (2017)

lower relative to high tide. Net TEP production rates were generally balanced (TEP production $=$ TEP consumption) except for 3 days in August (Fig. 2c). Over these days, there was a significantly higher $(p<0.05)$ net TEP production rate at low tide relative to high tide at two time points, and one time point where the reverse occurred.

\section{Diel}

Across the 48-h sampling period, TEP concentrations ranged from $78 \pm 9$ to $231 \pm 2 \mu \mathrm{g} \mathrm{XG}$ eq. $\mathrm{L}^{-1}$ (Fig. 3a). TEP concentrations were significantly higher $(p<0.01)$ at 20:00, 2 hours post- 
sunset, with TEP concentrations at this time point approximately double those observed at all other time points. The ratio of TEP:chl ranged from $85 \pm 18$ to $221 \pm 3$ over the sampling period (Fig. 2b). TEP:chl ratios shared a similar pattern to bulk TEP, with significantly higher $(p<0.03)$ TEP:chl ratios observed at 20:00 relative to all other time points. Interestingly, net TEP production rates were highest during the daylight hours relative to the night (Fig. 3c), with the highest net TEP production rates of $1.12 \mu \mathrm{g}$ XG eq. $\mathrm{L}^{-1} \mathrm{~d}^{-1}$ observed at 12:00.

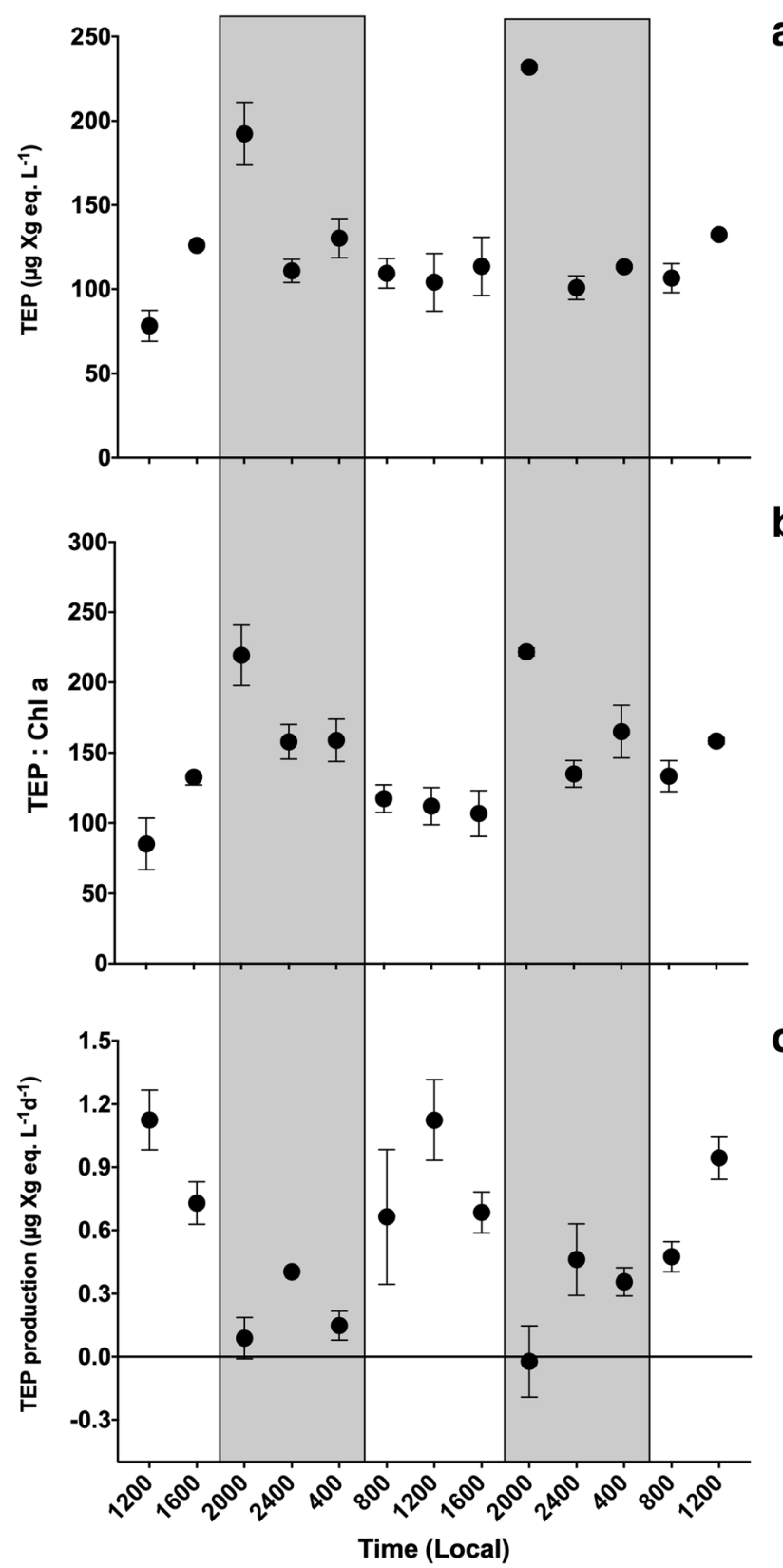

Fig. 3 Diel measurements of a TEP concentration ( $\mu \mathrm{g}$ XG eq. $\left.\mathrm{L}^{-1}\right)$, b TEP to chlorophyll ratio, and $\mathbf{c}$ TEP production rates $\left(\mu \mathrm{g} \mathrm{XG} \mathrm{eq.} \mathrm{L}^{-1} \mathrm{~d}^{-1}\right)$. Dark shaded areas represent night. Symbols are the mean of triplicate measurements, and error bars represent one standard deviation from the mean. Time of sampling (local Eastern Time) is shown on the $x$-axis

\section{Relationship with Environmental and Biological Variables}

Most metadata variables over the weekly dataset (15 out of 23) followed a non-normal distribution (Shapiro-Wilks < $0.05)$, and so, we applied Spearman rank correlations $(\rho)$ to observe TEP relationships. TEP measurements (concentration, production, and TEP:chl ratio) had significant relationships $(p \leq 0.05)$ with a range of metadata variables, often being correlated to different variables on different time scales (Fig. 4). On seasonal time scales, TEP concentration exhibited significant $(p<0.01)$ and positive correlations with temperature $(\rho=0.56)$, bulk chlorophyll $(\rho=0.47)$, and silicate $(\rho=$ 0.47 ; Fig. 4a). A range of other variables had significant yet weaker relationships with TEP concentration, including correlations that were positive (e.g., $\mathrm{Chl} \mu 0, g$, and solar radiation; $\rho>0.36$ ) and negative (e.g., Chl $r$ and ciliates; $\rho<-$ 0.39 ). Only a handful of variables were significantly correlated with TEP production rates (PON; $\rho=-0.44$ ) or TEP:chl ratios $\left(\mathrm{NH}_{4}\right.$ and tide height; $\left.\rho>0.35\right)$ on seasonal scales (Fig. 4a).

Over the tidal cycle, TEP concentration had a significant $(p \leq 0.05)$ and strong positive relationship with bulk chlorophyll $(\rho=0.5)$ and a strong negative relationship with chlorophyll accumulation rates $(\rho=-0.55$; Fig. 4B). Tidal TEP production rates were positively correlated with group-specific plankton biomass (e.g., nanoeukaryotes and heterotrophic dinoflagellates; $\rho>0.53$ ), while TEP:chl ratios were negatively correlated with picoeukaryote biomass $(\rho=-0.6)$ and chlorophyll grazing rates $(\rho=-0.52$; Fig. $4 b)$. On diel cycles, only three variables (CDOM, PAR, and salinity) had significant $(p<0.04)$ and strong correlations $(\rho>0.6$ or $<-0.6)$ with TEP, though the sign of these correlations varied with TEP measurements (Fig. 4c).

When all time points were aggregated, a positive and significant correlation $(\rho=0.77 ; p<0.001)$ was found between TEP and bulk chlorophyll concentration (Fig. S1). This strong relationship $(\rho=0.74)$ was maintained even after removing the two highest TEP $\left(>1000 \mu \mathrm{g}\right.$ XG eq. $\left.\mathrm{L}^{-1}\right)$ and chlorophyll $\left(>10 \mu \mathrm{g} \mathrm{L}^{-1}\right.$ ) values recorded at low tide. In addition, combining all datasets together, a negative and significant correlation $(\rho=-0.48 ; p<0.001)$ was found between TEP concentration and TEP production rates (Fig. S2). This relationship was maintained $(\rho=-0.46 ; p<0.001)$, with the removal of the highest TEP and chlorophyll values that are outliers, relative to the bulk of the data.

\section{Discussion}

Here, we provide further evidence of significant temporal trends in TEP concentration and production rates, dependent on the time scale examined, within a productive estuarine 
a

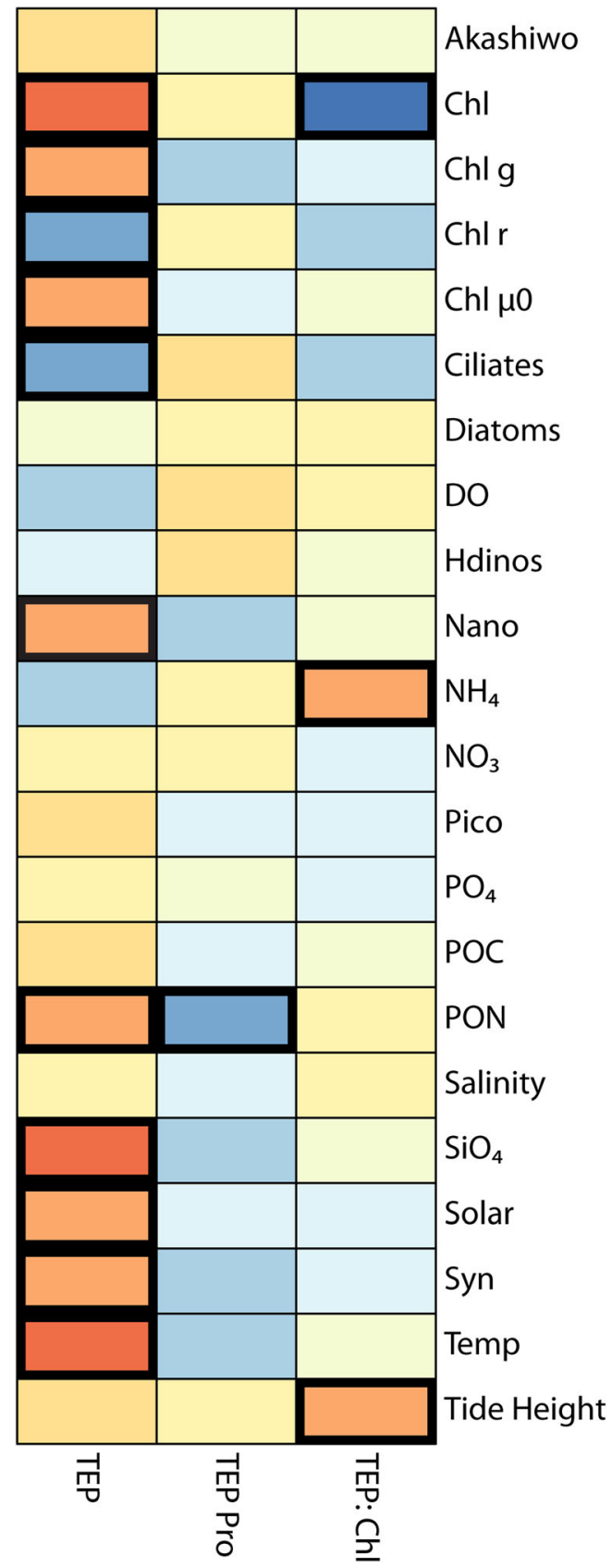

Fig. 4 Heatmap of Spearman correlation coefficients $(\rho)$ between average TEP measurements (concentration, production, and TEP:chl) and metadata variables that were sampled on a seasonal, $\mathbf{b}$ tidal, and $\mathbf{c}$ diel time scales. Seasonal and tidal heatmaps share a color gradient that maps to Spearman values, ranging from -0.6 (dark blue) to 0.6 (dark red).

system. Failure to consider temporal shifts in TEP concentrations or production rates may result in improper characterization of TEP dynamics, and thus, it remains critical to understand the temporal rhythms of TEP sources and sinks and to identify variables which are important in mediating TEP dynamics across a range of time scales.

\section{b Tidal}
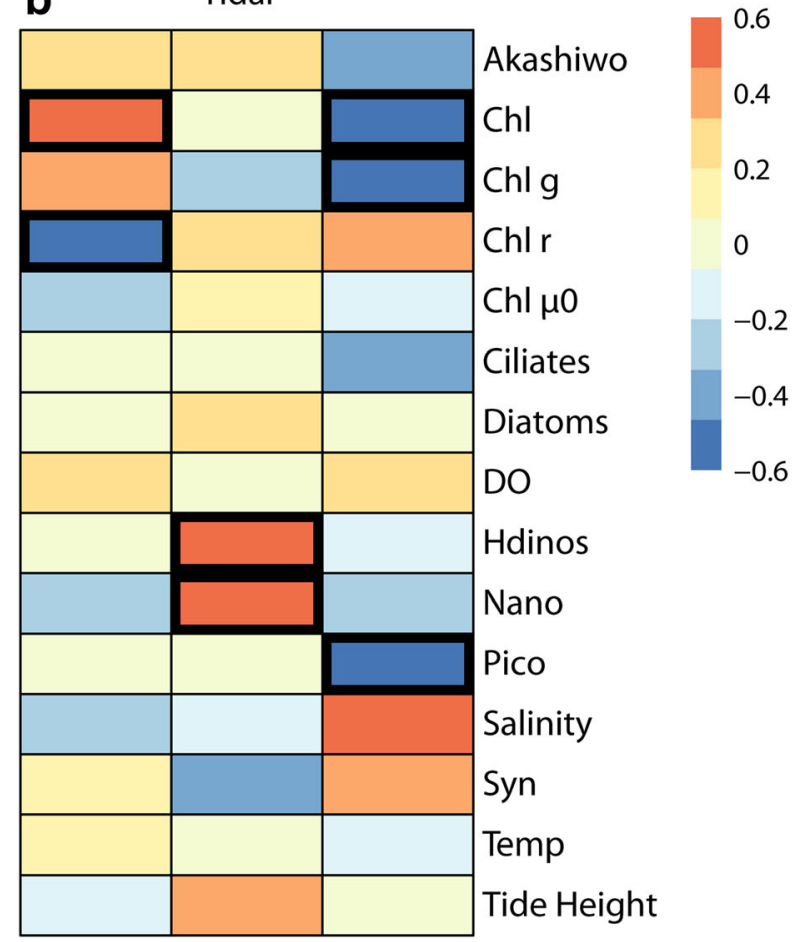

Hdinos

Nano

Pico

Salinity

Syn

Temp

Tide Height

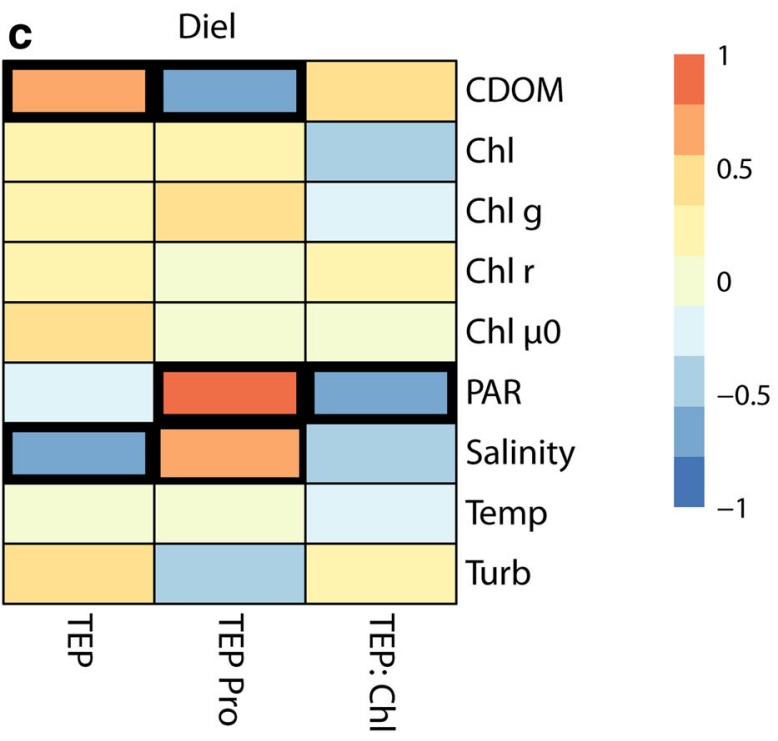

Correlations for the tidal heatmap have a similar blue-red gradient and range from -1 to 1 . For all heatmaps, black borders denote significant correlations ( $p$ value $\leq 0.05$ ). Raw data for all time intervals is accessible via the Github project link

While weekly TEP measurements in this study were in the range of those previously made in estuarine systems (Morelle et al. 2017; Ortega-Retuerta et al. 2018; Lee et al. 2020), we did not observe distinct trends in TEP concentration over the seasonal cycle. Other studies have noted seasonal TEP dynamics, with the highest TEP concentrations in the summer 
months when temperatures were elevated (Wetz et al. 2009; Ortega-Retuerta et al. 2018). Muted seasonal TEP dynamics we observed in the Skidaway River Estuary may reflect a lack of repetitive sampling over multiple years or the greater importance of physical features (e.g., strong tides or coastal runoff) that may structure TEP in this system. Estuaries, in general, have been shown to experience temporal variability in a suite of parameters including temperature, nutrients, and phytoplankton community composition (Cloern and Jassby 2010; Blauw et al. 2012; Anderson and Harvey 2019). Thus, changes in the physical and chemical characteristics of TEP are likely amplified in coastal environments due to dynamically shifting physical parameters (Azetsu-Scott and Passow 2004). While we did not detect clear seasonal signatures in TEP concentration (or TEP production), we found TEP to be strongly correlated to multiple factors like temperature, silicate, and chlorophyll. This suggests that primary production is important in mediating TEP dynamics in the estuary, which has been observed elsewhere (Morelle et al. 2017), and both biotic and abiotic factors can influence temporal variability in TEP throughout the course of a year.

Over tidal and diel time scales, clear trends in TEP concentrations were observed. Generally, TEP concentrations were significantly different between high and low tides, but with no clear pattern in terms of which tide had higher TEP. More strikingly, the TEP to chlorophyll ratio was almost always lower at low tide. Previous works in estuarine systems have observed positive correlations between TEP concentrations and salinity (Wetz et al. 2009). However, in this study, the range in salinity between the two tides was small (28.55-31.23 across both tides), thus, additional factors beyond salinity likely influenced the differences in TEP dynamics between tidal stages. From previous work published by our group on this system (Anderson et al. 2018), it is clear that there are significant differences in both the growth/mortality rates of phytoplankton and community composition of microbes between low and high tides. From the dataset presented here, chlorophyll and groupspecific plankton biomass (e.g., heterotrophic dinoflagellates and nanoflagellates) were significantly and positively correlated to TEP concentration and TEP production, respectively. Certain dinoflagellate species have been reported to be copious producers of TEP (Passow 2002a); however, it has been well established that the propensity for TEP production varies not only across phytoplankton groups but also within taxonomically similar groups (reviewed by Passow 2002b). In addition, microbes are not passive consumers of labile DOC in surface areas; increasing studies have shown the ability of microbes to "attack" phytoplankton cell surfaces, inducing release of easily degradable organic molecules (Mühlenbruch et al. 2018 and reference within), suggesting microbes may play a role in driving observed relationships between TEP and chlorophyll. It is important to note that physical factors, including turbulence, may have also played a role in mediating TEP dynamics between low and high tides. Though not measured directly in this study, other mesocosm- and lab-based experiments have demonstrated enhanced TEP production with turbulence (Beauvais et al. 2006; Rokkan Iversen et al. 2010; Burns et al. 2019), though such responses vary with nutrient conditions and composition of phytoplankton and bacteria. Together, our findings of tidal variability in bulk TEP and chlorophyll measurements are likely attributed to differences in the resident microbial community (e.g., compositional structure and interactions), as well as external factors such as nutrients and turbulence.

Over a diel cycle, TEP concentration, TEP:chlorophyll, and TEP production rates exhibited clear patterns. TEP concentration and TEP:chlorophyll peaked at dusk, whereas TEP production rates were highest at midday. Diel patterns in exuded phytoplankton metabolites have been observed in the ocean, with peaks in particulate metabolite concentrations at dusk (Boysen et al. 2020). In addition, biosynthesis of energyrich triacylglycerols also has a diel cycle, with peak production during the day (Becker et al. 2018). The dissolved polysaccharides that nucleate TEP aggregates could be released over similar diel rhythms, as a function of diel metabolic strategies that microbes use to balance redox stress and fuel energy. Moreover, it has been established that TEP is a source of food for copepods (Passow and Alldredge 1999); thus, TEP may be rapidly consumed overnight via diel vertically migrating copepods (Graham et al. 2000). Regardless of the mechanism of the diel TEP patterns observed, TEP concentrations and production rates increased at least two-fold over the course of a single day, highlighting the importance of considering temporal variability when examining TEP dynamics.

One potentially significant factor that is not accounted for in the current study is the impact that non-photosynthetic microbes may have on TEP production. Heterotrophic bacteria are tightly coupled with phytoplankton and respond rapidly to transient shifts in coastal phytoplankton communities, turning over phytoplankton-derived organic matter that drives ecosystem-wide biogeochemistry (Buchan et al. 2014). Previous literature has suggested that bacteria may produce extracellular polymeric substances that can form TEP (Passow 2002b; Ortega-Retuerta et al. 2010), while others have noted that bacteria may indirectly influence TEP production, via the release of enzymes that promote particle aggregation in closely associated phytoplankton (Gärdes et al. 2011; Cruz and Neuer 2019). Production of bacterially derived TEP may help to explain several patterns in our data, including the discrepancy between the high TEP concentrations and low TEP to chlorophyll ratio observed at high tide, as well as the similar diel pattern observed between TEP concentrations and the TEP to chlorophyll ratio. Further insight into temporal TEP dynamics should consider alternative TEP 
sources and pathways, such as those mediated by heterotrophic bacteria, which will require measurements of bacterial activity and composition.

Interestingly, despite a significant, negative correlation between TEP concentration and TEP production rate, often the magnitudes of these two metrics were offset from one another, especially on diel scales. It has been hypothesized that TEP precursor exudation may be the result of cellular carbon overflow, where nutrient limitation limits biomass production but not photosynthesis (Toggweiler 1993). A strong, positive correlation observed over a diel scale between TEP production and PAR supports the notion that cellular metabolic processes are the ultimate sources of the majority of TEP. From exudation of the dissolved precursors, the formation of TEP aggregates is dependent on a myriad of factors including spontaneous assembly (Chin et al. 1998), bubble adsorption (Mari 1999), and shear (Passow 2000). While these processes can happen rapidly, their influence on TEP production also varies over depth (Wurl et al. 2011), potentially creating a lag between when TEP is produced and when high TEP concentrations are observed in the environment at a given sampling depth. Therefore, in order to best predict TEP dynamics, and thereby carbon export, understanding the temporal variability in both TEP concentrations and production rates are vital to understanding TEP's role in carbon transport.

Combining all time scales, a significant correlation between bulk chlorophyll and TEP concentrations was observed, similar to numerous previous studies (Passow $2002 \mathrm{~b}$ ), suggesting phytoplankton are the primary sources of TEP precursory materials. Looking across all time scales, no "master" driver of TEP accumulation dynamics was observed; instead, this study observed time-specific drivers of TEP. However, this study did not measure all possible environmental parameters (e.g., turbulence, $\mathrm{pH}$, light intensity, and anthropogenic pollution) that may be important drivers of plankton and TEP dynamics in estuaries. Additionally, the tidal and diel temporal scale may not have had enough observations to demonstrate significant correlations between variables, relative to seasonal sampling that had a larger sample size and spanned a wider gradient of environmental conditions in the dataset. Building off the work presented here, there is a need for additional studies to better resolve the factors driving temporal dynamics of TEP concentrations and production rates. Further, researchers measuring TEP should take care to note the timing of TEP measurements and develop sampling schemes that resolves the full daily or seasonal range of TEP concentrations, depending on the overall research question. Ultimately, accurate predictions on the formation and fate of TEP in the ocean will rely on understanding TEP dynamics over time and incorporating these measurements into time series sampling, especially in complex ocean environments such as estuaries.
Acknowledgments We would like to thank T. Bittar, K. Bulski, D. Talmy, and the captain and crew of the R/V Savannah for help with diel sampling. We would also like to thank the Skidaway Institute of Oceanography and the University of Georgia for providing funding for ship use and sample processing.

Open Access This article is licensed under a Creative Commons Attribution 4.0 International License, which permits use, sharing, adaptation, distribution and reproduction in any medium or format, as long as you give appropriate credit to the original author(s) and the source, provide a link to the Creative Commons licence, and indicate if changes were made. The images or other third party material in this article are included in the article's Creative Commons licence, unless indicated otherwise in a credit line to the material. If material is not included in the article's Creative Commons licence and your intended use is not permitted by statutory regulation or exceeds the permitted use, you will need to obtain permission directly from the copyright holder. To view a copy of this licence, visit http://creativecommons.org/licenses/by/4.0/.

\section{References}

Alldredge, A.L., U. Passow, and B.E. Logan. 1993. The abundance and significance of a class of large, transparent organic particles in the ocean. Deep Sea Research Part I: Oceanographic Research Papers 40 (6): 1131-1140. https://doi.org/10.1016/0967-0637(93)90129-Q.

Anderson, S.R., and E.L. Harvey. 2019. Seasonal variability and drivers of microzooplankton grazing and phytoplankton growth in a subtropical estuary. Frontiers in Marine Science 7. https://doi.org/10. 3389/fmars.2019.00174.

Anderson, S.R., Q.P. Diou-Cass, and E.L. Harvey. 2018. Short-term estimates of phytoplankton growth and mortality in a tidal estuary: tidal growth and mortality. Limnology and Oceanography 63 (6): 2411-2422. https://doi.org/10.1002/lno.10948.

Annane, S., L. St-Amand, M. Starr, E. Pelletier, and G.A. Ferreyra. 2015. Contribution of transparent exopolymeric particles (TEP) to estuarine particulate organic carbon pool. Marine Ecology Progress Series 529: 17-34. https://doi.org/10.3354/meps11294.

Azetsu-Scott, K., and U. Passow. 2004. Ascending marine particles: significance of transparent exopolymer particles (TEP) in the upper ocean. Limnology and Oceanography 49 (3): 741-748. https://doi. org/10.4319/lo.2004.49.3.0741.

Beauvais, S., M. L. Pedrotti, J. Egge, K. Iversen, and C. Marrasé. 2006. Effects of turbulence on TEP dynamics under contrasting nutrient conditions: implications for aggregation and sedimentation processes. Marine Ecology Progress Series 323: 47-57. https://doi.org/10. 3354/meps323047.

Becker, K.W., J.R. Collins, B.P. Durham, R.D. Groussman, A.E. White, H.F. Fredricks, J.E. Ossolinski, D.J. Repeta, P. Carini, E.V. Armbrust, and B.A.S. van Mooy. 2018. Daily changes in phytoplankton lipidomes reveal mechanisms of energy storage in the open ocean. Nature Communications 9 (1): 5179. https://doi.org/10.1038/ s41467-018-07346-z.

Bhaskar, P.V., and N.B. Bhosle. 2006. Bacterial extracellular polymeric substance (EPS): a carrier of heavy metals in the marine food-chain. Environment International 32. Mar Pollution and Ecotoxicology: 191-198. https://doi.org/10.1016/j.envint.2005.08.010.

Bittar, T.B., U. Passow, L. Hamaraty, K.D. Bidle, and E.L. Harvey. 2018. An updated method for the calibration of transparent exopolymer particle measurements: updated TEP calibration method. Limnology 
and Oceanography: Methods 16 (10): 621-628. https://oi.org/10. 1002/lom3.10268.

Blauw, A.N., E. Benincà, R.W.P.M. Laane, N. Greenwood, and J. Huisman. 2012. Dancing with the tides: fluctuations of coastal phytoplankton orchestrated by different oscillatory modes of the tidal cycle. PLOS ONE 7: Public Library of Science: e49319. https://doi. org/10.1371/journal.pone.0049319.

Boyd, P.W., and T.W. Trull. 2007. Understanding the export of biogenic particles in oceanic waters: Is there consensus? Progress in Oceanography 72 (4): 276-312. https://doi.org/10.1016/j.pocean. 2006.10.007.

Boysen, A.K., L.T. Carlson, B.P. Durham, R.D. Groussman, F.O. Aylward, F. Ribalet, K.R. Heal, E.F. DeLong, E.V. Armbrust, and A.E. Ingalls. 2020. Diel Oscillations of Particulate Metabolites Reflect Synchronized Microbial Activity in the North Pacific Subtropical Gyre. bioRxiv. Cold Spring Harbor Laboratory: 2020.05.09.086173. https://doi.org/10.1101/2020.05.09.086173.

Buchan, A., G. R. LeCleir, C. A. Gulvik, and J. M. González. 2014. Master recyclers: features and functions of bacteria associated with phytoplankton blooms. Nature Reviews. Microbiology 12: 686-698. https://doi.org/10.1038/nrmicro3326.

Burns, W.G., A. Marchetti, and K. Ziervogel. 2019. Enhanced formation of transparent exopolymer particles (TEP) under turbulence during phytoplankton growth. Journal of Plankton Research 41 (3): 349361.

Chin, W., M. V. Orellana, and P. Verdugo. 1998. Spontaneous assembly of marine dissolved organic matter into polymer gels. Nature 391 . Nature Publishing Group: 568-572. https://doi.org/10.1038/35345.

Cloern, J.E., and A.D. Jassby. 2010. Patterns and scales of phytoplankton variability in estuarine-coastal ecosystems. Estuaries and Coasts 33 (2): 230-241. https://doi.org/10.1007/s12237-009-9195-3.

Cruz, B.N., and S. Neuer. 2019. Heterotrophic bacteria enhance the aggregation of the marine picocyanobacterial Prochlorococcus and Synechococcus. Frontiers in Microbiology 10. https://doi.org/10. 3389/fmicb.2019.01864.

de Vicente, I., E. Ortega-Retuerta, O. Romera, R. Morales-Baquero, and I. Reche. 2009. Contribution of transparent exopolymer particles to carbon sinking flux in an oligotrophic reservoir. Biogeochemistry 96 (1-3): 13-23. https://doi.org/10.1007/s10533-009-9342-8.

Egge, J.K., T.F. Thingstad, A. Larsen, A. Engel, J. Wohlers, R.G.J. Bellerby, and U. Riebesell. 2009. Primary production during nutrient-induced blooms at elevated $\mathrm{CO}_{2}$ concentrations. Biogeosciences 6: 877-885. https://doi.org/10.5194/bg-6-877-2009.

Engel, A. 2004. Distribution of transparent exopolymer particles (TEP) in the Northeast Atlantic Ocean and their potential significance for aggregation processes. Deep Sea Research Part I: Oceanographic Research Papers 51 (1): 83-92. https://doi.org/10.1016/j.dsr.2003. 09.001

Engel, A., J. Piontek, K. Metfies, S. Endres, P. Sprong, I. Peeken, S. Gäbler-Schwarz, and E. Nöthig. 2017. Inter-annual variability of transparent exopolymer particles in the Arctic Ocean reveals high sensitivity to ecosystem changes. Scientific Reports 7. Nature Publishing Group: 1-9. https://doi.org/10.1038/s41598-01704106-9.

Falkowski, P.G., T. Algeo, L. Codispoti, C. Deutsch, S. Emerson, B. Hales, R.B. Huey, W.J. Jenkins, L.R. Kump, L.A. Levin, T.W. Lyons, N.B. Nelson, O.S. Schofield, R. Summons, L.D. Talley, E. Thomas, F. Whitney, and C.B. Pilcher. 2011. Ocean deoxygenation: past, present, and future. Eos, Transactions American Geophysical Union 92 (46): 409-410. https://doi.org/10.1029/2011EO460001.

Gärdes, A., M.H. Iversen, H.P. Grossart, U. Passow, and M.S. Ullrich. 2011. Diatom-associated bacteria are required for aggregation of Thalassiosira weissflogii. ISME 5 (3): 436-445.

Graff, J.R., and T.A. Rynearson. 2011. Extraction method influences the recovery of phytoplankton pigments from natural assemblages.
Limnology and Oceanography: Methods 9 (4): 129-139. https:// doi.org/10.4319/lom.2011.9.129.

Graham, M., S. MacIntyre William, and A.L. Alldredge. 2000. Diel variations of marine snow concentration in surface waters and implications for particle flux in the sea. Deep Sea Research Part I: Oceanographic Research Papers 47 (3): 367-395. https://doi.org/ 10.1016/S0967-0637(99)00063-1.

Heip, C.H.R., N.K. Goosen, P.M.J. Herman, J.C. Kromkamp, J.J. Middelburg, K.E.R. Soetaert, Spatial Ecology, Marine Microbiology, and Ecosystems Studies. 1995. Production and consumption of biological particles in temperate tidal estuaries. Oceanography and Marine Biology: an annual review 33. Taylor \& Francis Group: 1-149.

Henson, S.A., A. Yool, and R. Sanders. 2015. Variability in efficiency of particulate organic carbon export: a model study. Global Biogeochemical Cycles 29 (1): 33-45. https://doi.org/10.1002/ $2014 \mathrm{~GB} 004965$.

Hopkinson, C.S., and E.M. Smith. 2005. Estuarine respiration: an overview of benthic, pelagic, and whole system respiration. In Respiration in aquatic ecosystems, ed. Paul del Giorgio and Peter Williams, 122-146. Oxford University Press. https://doi.org/10. 1093/acprof:oso/9780198527084.003.0008.

Jespersen, A.M., and K. Christoffersen. 1987. Measurements of chlorophyll a from phytoplankton using ethanol as extraction solvent. Archiv für Hydrobiologie 109: 445-454.

Kolde, R. 2012. pheatmap: Pretty Heatmaps. R package version 1.0.12.. http://cran.r-project.org/package=pheatmap.

Landry, M.R., and R.P. Hassett. 1982. Estimating the grazing impact of marine micro-zooplankton. Marine Biology 67 (3): 283-288. https:// doi.org/10.1007/BF00397668.

Lee, J.H., W.C. Lee, H.C. Kim, N. Jo, H.K. Jang, J.J. Kang, D. Lee, K. Kim, and S.H. Lee. 2020. Transparent exopolymer particle (TEPS) dynamics and contribution to particulate organic carbon (POC) in Jaran Bay, Korea. Water 12, 1057. Multidisciplinary Digital Publishing Institute. https://doi.org/10.3390/w12041057.

Malpezzi, M.A., L.P. Sanford, and B.C. Crump. 2013. Abundance and distribution of transparent exopolymer particles in the estuarine turbidity maximum of Chesapeake Bay. Marine Ecology Progress Series 486: 23-35. https://doi.org/10.3354/meps10362.

Mari, X. 1999. Carbon content and C:N ratio of transparent exopolymeric particles (TEP) produced by bubbling exudates of diatoms. Marine Ecology Progress Series 183: 59-71. https://doi.org/10.3354/ meps 183059.

Mari, X., U. Passow, C. Migon, A.B. Burd, and L. Legendre. 2017. Transparent exopolymer particles: effects on carbon cycling in the ocean. Progress in Oceanography 151: 13-37. https://doi.org/10. 1016/j.pocean.2016.11.002.

Morelle, J., M. Schapira, and P. Claquin. 2017. Dynamics of phytoplankton productivity and exopolysaccharides (EPS and TEP) pools in the seine estuary (France, Normandy) over tidal cycles and over two contrasting seasons. Marine Environmental Research 131: 162176. https://doi.org/10.1016/j.marenvres.2017.09.007.

Morison, F., and S. Menden-Deuer. 2017. Doing more with less? Balancing sampling resolution and effort in measurements of protistan growth and grazing-rates. Limnology and Oceanography: Methods 15 (9): 794-809. https://doi.org/10.1002/lom3.10200.

Mühlenbruch, M., H. Grossart, F. Eigemann, and M. Voss. 2018. Minireview: phytoplankton-derived polysaccharides in the marine environment and their interactions with heterotrophic bacteria. Environmental Microbiology 20 (8): 2671-2685. https://doi.org/ $10.1111 / 1462-2920.14302$.

Ortega-Retuerta, E., C.M. Duarte, and I. Reche. 2010. Significance of bacterial activity for the distribution and dynamics of transparent exopolymer particles in the Mediterranean Sea. Microbial Ecology 59 (4): $808-818$. 
Ortega-Retuerta, E., C. Marrasé, A. Muñoz-Fernández, M.M. Sala, R. Simó, and J.M. Gasol. 2018. Seasonal dynamics of transparent exopolymer particles (TEP) and their drivers in the coastal NW Mediterranean Sea. Science of the Total Environment 631-632: 180-190. https://doi.org/10.1016/j.scitotenv.2018.02.341.

Passow, U. 2000. Formation of transparent exopolymer particles, TEP, from dissolved precursor material. Marine Ecology Progress Series 192: 1-11. https://doi.org/10.3354/meps 192001 .

Passow, U. 2002a. Production of transparent exopolymer particles (TEP) by phyto- and bacterioplankton. Marine Ecology-Progress Series 236: $1-12$.

Passow, U. 2002b. Transparent exopolymer particles (TEP) in aquatic environments. Progress in Oceanography 55 (3-4): 287-333. https://doi.org/10.1016/S0079-6611(02)00138-6.

Passow, U. 2012. The abiotic formation of TEP under different ocean acidification scenarios. Marine Chemistry 128-129: 72-80. https:// doi.org/10.1016/j.marchem.2011.10.004.

Passow, U., and A.L. Alldredge. 1995. Aggregation of a diatom bloom in a mesocosm: the role of transparent exopolymer particles (TEP). Deep Sea Research Part II: Topical Studies in Oceanography 42 (1): 99-109. https://doi.org/10.1016/0967-0645(95)00006-C.

Passow, U., and A.L. Alldredge. 1999. Do transparent exopolymer particles (TEP) inhibit grazing by the euphausiid Euphausia pacifica? Journal of Plankton Research 21. Oxford Academic 21 (11): 2203 2217. https://doi.org/10.1093/plankt/21.11.2203.

Rokkan Iversen, K., R. Primicerio, A. Larsen, J.K. Egge, F. Peters, Ó. Guadayol, et al. 2010. Effects of small-scale turbulence on lower trophic levels under different nutrient conditions. Journal of Plankton Research 32 (2): 197-208.

Shapiro, S. S., and M. B. Wilk. 1965. An analysis of variance test for normality (complete samples). Biometrika 52. [Oxford University Press, Biometrika Trust]: 591-611. JSTOR. https://doi.org/10.2307/ 2333709.

Toggweiler, J. R. 1993. Carbon overconsumption. Nature 363. Nature Publishing Group: 210-211. https://doi.org/10.1038/363210a0.

Wetz, M.S., M.C. Robbins, and H.W. Paerl. 2009. Transparent exopolymer particles (TEP) in a river-dominated estuary: spatialtemporal distributions and an assessment of controls upon TEP formation. Estuaries and Coasts 32 (3): 447-455. https://doi.org/10. 1007/s12237-009-9143-2.

Wurl, O., L. Miller, and S. Vagle. 2011. Production and fate of transparent exopolymer particles in the ocean. Journal of Geophysical Research: Oceans 116. https://doi.org/10.1029/2011JC007342.

Zamanillo, M., E. Ortega-Retuerta, S. Nunes, P. Rodríguez-Ros, M. Dall'Osto, M. Estrada, M. M. Sala, and R. Simó. 2019a. Main drivers of transparent exopolymer particle distribution across the surface Atlantic Ocean. Biogeosciences 16. Copernicus GmbH: 733-749. https://doi.org/10.5194/bg-16-733-2019.

Zamanillo, M., E. Ortega-Retuerta, S. Nunes, M. Estrada, M.M. Sala, S. Royer, D.C. López-Sandoval, et al. 2019b. Distribution of transparent exopolymer particles (TEP) in distinct regions of the Southern Ocean. Science of the Total Environment 691: 736-748. https://doi. org/10.1016/j.scitotenv.2019.06.524. 